\title{
Preparation of starch-based scaffolds for tissue engineering by supercritical immersion precipitation
}

\author{
Ana Rita C. Duarte ${ }^{a, b, *}$, João F. Mano ${ }^{a, b}$, Rui L. Reis ${ }^{a, b}$ \\ a 3B's Research Group - Biomaterials, Biodegradables and Biomimetics, Dept. of Polymer Engineering, University of Minho, Headquarters of the European Institute of Excellence \\ on Tissue Engineering and Regenerative Medicine, AvePark, Zona Industrial da Gandra, S. Cláudio do Barco, 4806-909 Caldas das Taipas, Guimarães, Portugal ${ }^{1}$ \\ ${ }^{\mathrm{b}}$ IBB-Institute for Biotechnology and Bioengineering, PT Associated Laboratory (Laboratório Associado), Portugal ${ }^{2}$
}

\section{A R T I C L E I N F O}

\section{Article history:}

Received 28 July 2008

Accepted 15 December 2008

\section{Keywords:}

Supercritical fluids

PLLA

Immersion precipitation

Phase inversion

Natural polymers

Scaffolds

Tissue engineering

\begin{abstract}
A B S T R A C T
The aim of this study was to evaluate the possibility of preparing starch-based porous matrixes using supercritical fluid technology. Supercritical immersion precipitation technique was used to prepare scaffolds of a polymeric blend of starch and poly(L-lactic acid) for tissue engineering purposes.Immersion precipitation experiments were carried out at different operational conditions and highly porous and interconnected scaffolds were obtained. Two organic solvents, dichloromethane and chloroform were tested, and from the results obtained chloroform was the more favourable for the process. The effect of polymer solution concentration ( 5 up to $20 \mathrm{wt} \%$ ), temperature ( 35 up to $55^{\circ} \mathrm{C}$ ) and pressure (100 up to $200 \mathrm{bar}$ ) in the SPLA (50:50 wt\%) membrane morphology, porosity and interconnectivity was evaluated. All the conditions tested were in the region of total miscibility between the organic solvent and carbon dioxide. Additionally, a blend with a different starch-poly(L-lactic acid) ratio (30:70 wt\%) was tested. Bicontinuous structures were formed indicating that the $\mathrm{L}-\mathrm{L}$ demixing process that governs the phase inversion is the spinodal decomposition.
\end{abstract}

(C) 2008 Elsevier B.V. All rights reserved.

\section{Introduction}

Ideal scaffolds should be biocompatible, biodegradable and promote cellular interactions and tissue development and possess proper mechanical and physical properties [1]. A wide variety of materials have been used for the preparation of scaffolds, from metals to ceramics and polymers. Special attention should be paid to polymers as they present the most versatile class of materials. Although synthetic biodegradable polymers have been widely used for tissue engineering, natural polymers have unique, intrinsic properties that make them appealing to be used as scaffolds [2]. Natural polymers are in general non-toxic, even in large concentrations, mucoadhesive, biocompatible, and biodegradable [2,3,4].

Starch-based polymers have been studied in our group for a wide range of bone-related therapy applications, ranging from tissue engineering scaffolds $[5,6,7,8,9]$, to bone cements $[10,11]$ and drug delivery systems $[12,13]$. Its natural origin, together with its mechanical properties and biocompatibility support the potential of starch-based materials in the biomedical field [14].

\footnotetext{
* Corresponding author. Fax: +351 253510909.

E-mail address: aduarte@dep.uminho.pt (A.R.C. Duarte).

${ }^{1}$ http://www.3bs.uminho.pt.

2 www.ibb.pt.
}

One of the most important stages of tissue engineering is the design and processing of a porous 3D structure, with high porosity, high interconnectivity between the porous and uniform distribution. A variety of processing techniques have been developed and include solvent casting and particles leaching, compression moulding and particle leaching, thermally induced phase separation, gas-foaming processes, among others [15]. The main disadvantages of these methods are the use of organic solvents and the high temperatures required. The presence of residual organic solvents is being rigorously controlled by international safety regulations, thus it is necessary to warrant the complete removal and absence of these substances. Supercritical fluid technology appears to be, therefore an interesting alternative to the traditional processing methods [16,17].

Carbon dioxide is the most commonly used supercritical fluid as it has mild critical parameters, it is environmentally benign, non-toxic, nonflammable, noncorrosive, ready available and inexpensive. Its elimination and the recovery of final products are easier (no residue is left and a dry solid product is easily obtained, just by controlling the pressure), leading to processes with less energy consumption [18].

Different techniques have been proposed for the preparation of scaffolds for tissue engineering, namely gas foaming or phase inversion [19]. Gas foaming takes advantage of the plasticizing properties of carbon dioxide. In this technique, the polymer is exposed to carbon dioxide, which plasticizes it by reducing the glass transition 


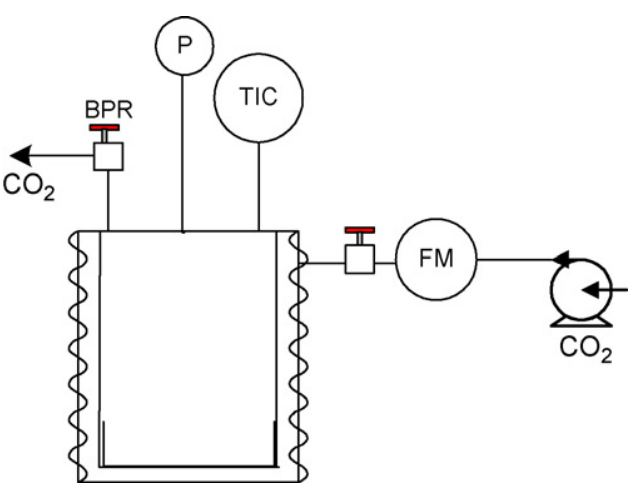

Fig. 1. Schematic diagram of the high pressure phase-inversion apparatus (P, pressure transducer; TIC, temperature controller; FM, flowmeter; BPR, back pressure regulator).

temperature or melting point. On venting the $\mathrm{CO}_{2}$ by depressurization, thermodynamic instability causes supersaturation of the carbon dioxide dissolved in the polymer matrix and hence, nucleation of cells occurs [20]. This technique is limited by the high glass transitions of the crystalline polymers and is therefore more commonly to amorphous polymers.

The immersion precipitation technique, also known as phaseinversion method, involves casting of a polymer solution onto an inert support followed by immersion of the support with the cast film into a bath filled with a non-solvent for the polymer. The contact between the solvent and the non-solvent causes the solution to be phase-separated. If the non-solvent used is a supercritical fluid this adds several advantages to the process. One of the most important advantages of the use of carbon dioxide is the fact that simply by tuning the process conditions, i.e. pressure and temperature one can tailor the final structure of the product. Additionally, when carbon dioxide is used as a non-solvent a subsequent drying step is avoided and the porous structure obtained is a dry product free of any residual solvent.

The use of carbon dioxide as a non-solvent for phase separation has been successfully reported in the literature for example for PLLA [21,22], PMMA [23], Nylon 6 [24], PS [25], cellulose acetate [26,27], polysulfone [28-30] and polycarbonate/PEG [31]. However, it has never been reported the processing of natural-based polymers using this technique. In this work the possibility of processing a natural-based polymer is evaluated. Process variables, such as polymer concentration, temperature and pressure have a strong influence in the porosity of the scaffolds obtained and were for that reason extensively studied.

\section{Experimental procedure}

\subsection{Materials}

Commercial blends of starch and poly-L-lactic acid (SPLA 50:50 and 30:70 wt\%) were obtained from Novamont, Italy. Dichloromethane, DCM (CAS 78-09-2, 99.9\% purity) and chloroform (CAS 67-68-5, 99.9\% purity) were purchased from Vaz Pereira. Carbon dioxide ( $99.998 \mathrm{~mol} \%$ ) was supplied by Air Liquide. All chemicals were used with no further purification.

\subsection{Supercritical assisted phase-inversion process}

The phase-inversion experiments were carried out in an apparatus, similar to the one schematically presented in Fig. 1.

In each experiment a small amount (ca. $2 \mathrm{ml}$ ) of the polymer solution is loaded in a stainless steel cap with $2 \mathrm{~cm}$ diameter, which is placed inside the high pressure vessel. The vessel is heated in by means of an electric thin band heater (OGDEN) connected to a temperature controller, that maintains temperature within $\pm 1^{\circ} \mathrm{C}$ (TC). Carbon dioxide is pumped into the vessel using high pressure piston pump (P-200A Thar Technologies) until the operational pressure is attained. The pressure inside the vessel is measured with a pressure transducer $(\mathrm{P})$. The system was closed for $45 \mathrm{~min}$ to allow the occurrence of phase separation. Afterwards the system is flushed for another $45 \mathrm{~min}$, with a stream of carbon dioxide at very low flow rate $(5 \mathrm{~g} / \mathrm{min})$, in order to ensure complete drying of the scaffolds. The flow is regulated by a flow meter (FM-Siemens, SITRANS FC MASS FLO MASS2100). The outflow is regulated by a back pressure valve (Go, Inc., USA).

\subsection{Scaffold characterization}

\subsubsection{Scanning Electron Microscopy-SEM}

Samples of the scaffolds prepared were observed by a Leica Cambridge S360 Scanning Electron Microscope (SEM). The films were fixed by mutual conductive adhesive tape on aluminium stubs and covered with gold palladium using a sputter coater.

\subsubsection{Micro-computed tomography}

The inner structure, porosity and interconnectivity were evaluated by micro-computerized tomography using a Scanco 20 equipment (Scanco Medicals, Switzerland) with penetrative X-rays of $40 \mathrm{keV}$. The X-ray scans were acquired in high-resolution mode $(39.39 \mu \mathrm{m})$. CT Analyser ${ }^{\circledR}$ (SkyScan, Belgium) was used to visualize the 2D X-ray sections images of the scaffolds.

\subsubsection{Mechanical properties}

Compressive mechanical properties of the scaffolds prepared were measured using an INSTRON 4301 (Instron Int. Ltd., High Wycombe, UK). The compressive modulus is defined as the initial linear modulus on the stress/strain curves. The data presented is the result of the average of at least five measurements.

\section{Results and discussion}

In this study the possibility of preparing SPLA scaffolds with potential application in tissue engineering using supercritical fluid technology is evaluated. The final morphology of the scaffolds obtained varies greatly with the properties of the materials and the process conditions. A summary of the experiments performed is listed in Table 1.

The experiments were designed in order to determine the best operational conditions for the production of SPLA scaffolds to be used for tissue engineering purposes. In each set of experiments one of the variables was modified so that, the effect of the different variables in the particle size could be evaluated.

Table 1

Summary of the experiments performed.

\begin{tabular}{llllll}
\hline Polymer & Experiment & Solvent & $\begin{array}{l}\text { Concentration } \\
(\text { wt } \%)\end{array}$ & $P($ bar $)$ & $T\left({ }^{\circ} \mathrm{C}\right)$ \\
\hline SPLA & 1 & Chloroform & 10 & 100 & 45 \\
50:50 & 2 & Dichloromethane & 10 & 100 & 45 \\
& 3 & Chloroform & $5^{\mathrm{a}}$ & 100 & 45 \\
& 4 & Chloroform & 15 & 100 & 45 \\
& 5 & Chloroform & 20 & 100 & 45 \\
& 6 & Chloroform & 10 & 100 & 35 \\
& 7 & Chloroform & 10 & 100 & 55 \\
& 8 & Chloroform & 10 & 150 & 45 \\
& 9 & Chloroform & 10 & 200 & 45 \\
SPLA & 10 & Chloroform & 10 & 100 & 45 \\
30:70 & 11 & Chloroform & 10 & 100 & 55 \\
\hline
\end{tabular}

a Polymer concentration too low to obtain a membrane. 

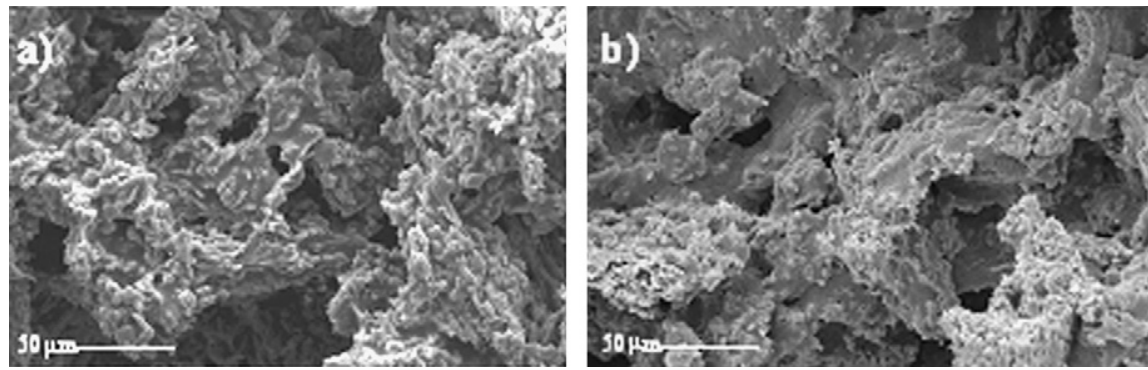

Fig. 2. SEM images of the matrixes prepared from (a) chloroform solution and (b) dichloromethane solution.

The supercritical assisted phase-inversion process relies on two mechanisms that take place at the same time, namely the diffusion of carbon dioxide into the polymer solution and the extraction of the organic solvent by the supercritical fluid. The high solubility between the organic solvent and the anti-solvent will favour the process, as this means a higher affinity of the solvent to the carbon dioxide, which will cause the phase separation and the precipitation of the polymer with a porous structure. Therefore, the selection of a proper combination of the organic solvent and the antisolvent for a particular polymer is essential for the success of the process. To determine the best organic solvent for the process two solutions of $10 \mathrm{wt} \%$ SPLA in chloroform and dichloromethane were prepared. The SEM images of the matrixes prepared are shown in Fig. 2. The structures obtained present large open pores $\sim 80 \mu \mathrm{m}$ and smaller pores spread all over the structure. Tsivintzelis and Pavlidou [21] prepared porous matrixes of PLLA from dichloromethane solutions and observed the formation of uniform cellular structures. However in this case, the pores are not interconnected. Comparing the results obtained by these authors and the ones presented in this work, we can conclude that the presence of starch in the polymeric mixture alters the phase behaviour of the system and using adequate processing conditions instead of a cellular structure a bicontinuos highly interconnected porous structure is formed.

From the results obtained, chloroform was chosen to be the best solvent for the process. It not only dissolves better the raw material (SPLA) as the structures formed are also thicker and more porous. The thickness of the samples is $1.65 \mathrm{~mm}$ and $1.00 \mathrm{~mm}$ when prepared from a chloroform or dichloromethane solution, respectively.

To evaluate the advantages of using carbon dioxide as a drying medium, a sample of polymer solution ( $10 \mathrm{wt} \%$ ) was left to dry in the stainless steel cap overnight. The film obtained was much thinner and did not present a porous structure.

\subsection{SPLA (50:50 wt\%) scaffolds}

\subsubsection{Effect of polymer concentration}

In a first approach the concentration of the polymer solution (experiments 1, 3, 4 and 5) was evaluated. The polymer concentration in the organic solution plays an important role in the final structure of the membrane obtained. In immersion precipitation at least three components are present in the system. A better understanding of the mechanisms involved in the process requires the knowledge of the ternary phase diagram of the components in the system. Fig. 3 presents a schematic representation of the phase diagram.

The complexity of the mechanisms involved in the process can be reduced if we consider the process isothermal; this is valid as long as the mixing heat between the solvent and non-solvent is not considerably high.

The boundary between the homogeneous phase and the liquid-liquid ( $\mathrm{L}-\mathrm{L}$ ) demixing gap is often called binodal and it corresponds to the cloud point curve of the polymer. Usually the region of
$\mathrm{L}-\mathrm{L}$ demixing is subdivided into a region of spinodal demixing. The grey area of the diagram corresponds to two different metastable regions where nucleation and growth take place.

According to the theory of Flory-Huggins the size and location of the demixing gap, as well of the critical point, depends on the molar volumes of the components present in the system and their interactions, i.e., polymer-solvent, polymer-non-solvent and solvent-non-solvent interactions [32].

The suggested mechanism responsible for the morphology of porous matrixes by phase inversion is the liquid-liquid demixing. However, the attribution of a specific structure in the membrane to a certain phase separation process is rather complicated [33]. Different mass transport mechanisms are involved in these regions and for that reason different polymeric matrixes can be obtained. The morphology of the matrixes prepared can be characterized according to four structural elements, namely cellular structures, nodules, bicontinuous structures or unconnected particles [34].

The equilibrium phase diagram represents the thermodynamically favoured processes that might occur during phase separation, nonetheless it is the kinetics that will determine to what extent the thermodynamically favoured phase transition will take place. Furthermore, non-equilibrium processes may play an important role during the membrane formation.

The majority of the matrixes are prepared by controlled phase separation of polymer solutions in two phases: one with a high polymer concentration and one with a low polymer concentration. A proposed mechanism of membranes formation indicates that a porous cellular structure is obtained if L-L demixing by nucleation and growth of the droplets of a polymer lean phase occurs [27].

Solutions with different polymer concentrations were tested. It was observed that at lower polymer concentrations, i.e., $5 \mathrm{wt} \%$ a rapid and large expansion of the solution by the non-solvent induces the precipitation of the polymer in the form of fine particles, as if a Gas Anti-Solvent process was performed. Besides this fact, at low concentrations the percentage of polymer present is not sufficient to form the solid continuous structure. On the contrary,

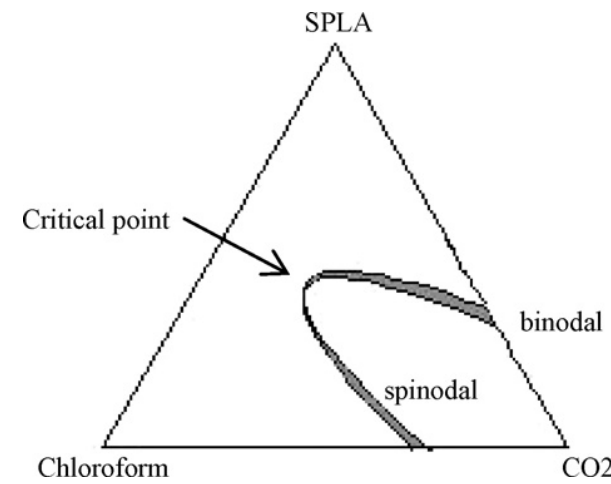

Fig. 3. Schematic representation of the ternary phase diagram of the components involved in the phase-inversion process. 

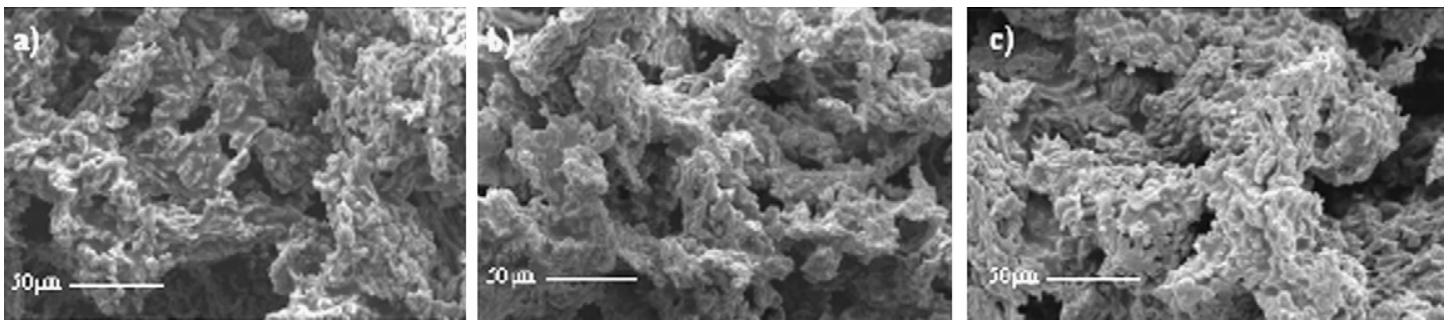

Fig. 4. Effect of polymer concentration in samples prepared at 100 bar and $45^{\circ} \mathrm{C}$ (a) $10 \mathrm{wt} \%$, (b) $15 \mathrm{wt} \%$, and (c) $20 \mathrm{wt} \%$.
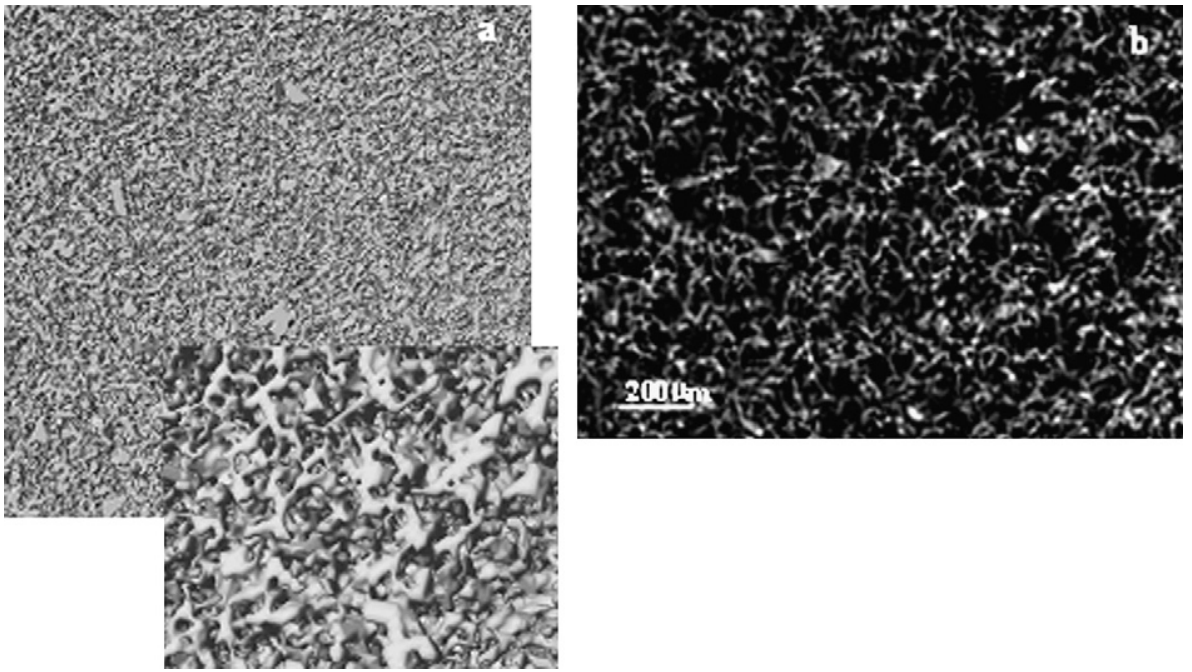

Fig. 5. Representative micro-CT images of SPLA matrix prepared at 100 bar and $45^{\circ} \mathrm{C}$ (a) 3D model and (b) $2 \mathrm{D}$ model.

when the concentration of the polymer solution is higher, the viscosity is also higher and the diffusion of the supercritical phase in the liquid is slower. That is to say, the demixing will occur slowly and the polymer will form a porous continuous structure.

In Fig. 4, the SEM images of the polymer matrixes prepared with different concentrations are presented.

The morphology of the SPLA matrixes obtained by supercritical assisted phase-inversion method can be considered as a bicontinuos structure. Besides the macropores $(\sim 75 \mu \mathrm{m})$ one can also identify the existence of micropores with sizes ranging from 10 to $20 \mu \mathrm{m}$ and the surfaces appear very rough. Such particular microstructures enhance the transport properties within the structure and could also encourage cell attachment and proliferation. These matrixes are also characterized by a highly interconnected porous structure. Ideal scaffolds for bone tissue engineering require three-dimensionally interconnected porous structures, so nutrients and oxygen can be accessible to the cells together with the elimination of cell wastes.

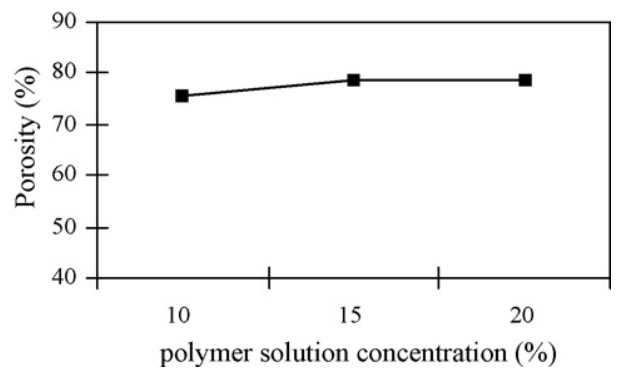

Fig. 6. Effect of the polymer concentration in the initial solution in the porosity of the structures prepared.
The mechanism proposed for the precipitation of these interconnected pore structures is a spinodal decomposition, nevertheless this is still object of discussion and another hypothesis is that the bicontinuos structures are a result of coalescence of polymer poor droplets generated by bimodal decomposition [33].

In the SEM images it is possible to notice already the interconnectivity of the pores, further analysis by micro-CT confirms these features. From micro-CT analysis it is also possible to calculate also the porosity of the samples.

\subsubsection{Micro-computed tomography}

Micro-computed tomography allows a better visualization of the inner structure of the matrixes prepared. An example of the 3D model of a SPLA matrix prepared by supercritical assisted phaseinversion method is shown in Fig. 5.

Fig. 5a demonstrates that the macroporous structure is homogeneous throughout all the volume of the sample. The representative

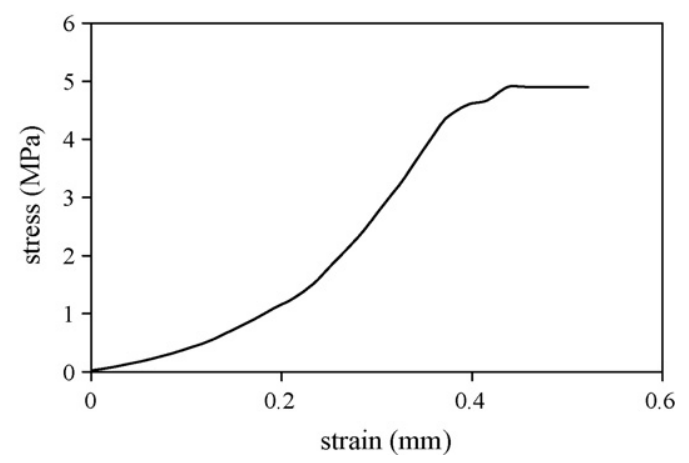

Fig. 7. Stress deformation curve of SPLA $20 \mathrm{wt} \%$ sample prepared at $45^{\circ} \mathrm{C}$ and $100 \mathrm{bar}$. 
Table 2

Mechanical properties of the matrixes prepared at $100 \mathrm{bar}$ and $45^{\circ} \mathrm{C}$ (standard deviation error is also presented).

\begin{tabular}{|c|c|c|c|c|}
\hline Polymer concentration in solution (\%) & Thickness (mm) & Compressive modulus (MPa) & Maximum stress (MPa) & Strain at maximum stress ( $\mathrm{mm}$ ) \\
\hline 10 & 1.5 & $0.11( \pm 0.01)$ & $2.75( \pm 0.63)$ & $0.46( \pm 0.15)$ \\
\hline 15 & 1.7 & $0.14( \pm 0.02)$ & $4.26( \pm 0.39)$ & $0.44( \pm 0.07)$ \\
\hline 20 & 1.9 & $0.15( \pm 0.02)$ & $4.84( \pm 0.82)$ & $0.43( \pm 0.08)$ \\
\hline
\end{tabular}
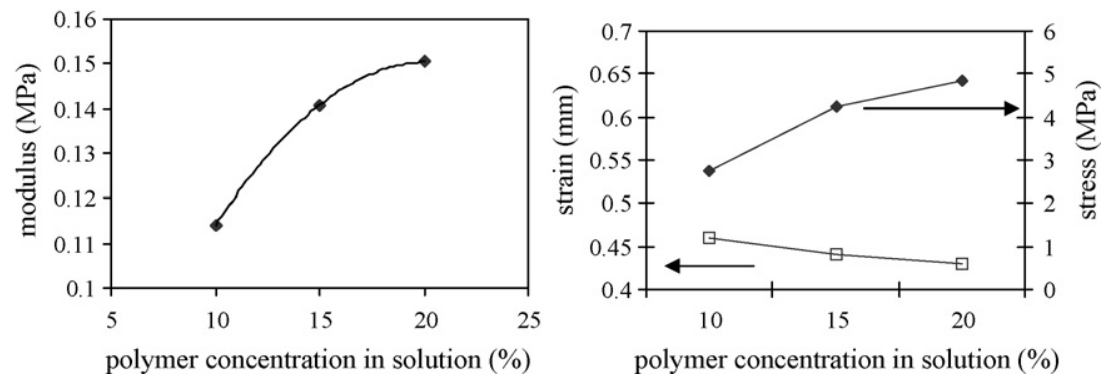

Fig. 8. Effect of the initial polymer concentration on the mechanical properties of the scaffolds prepared.
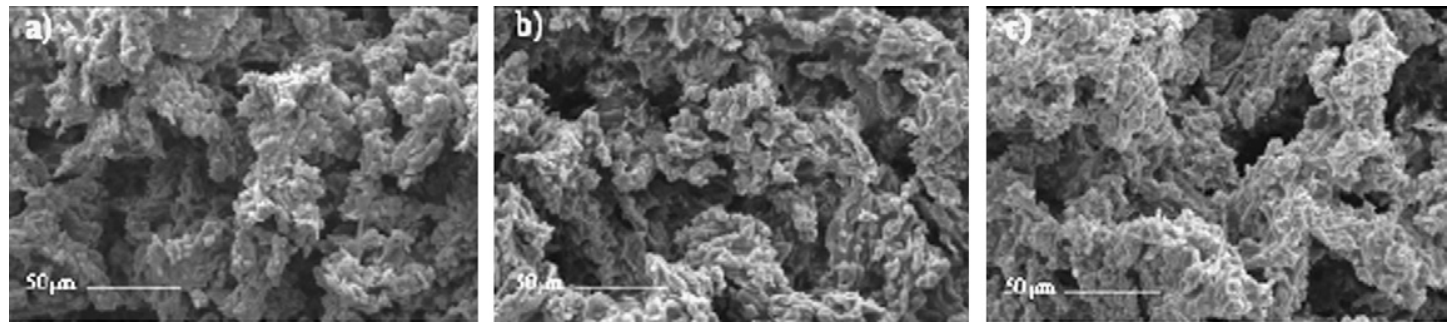

Fig. 9. Effect of pressure in the formation of SPLA porous matrixes, at $45^{\circ} \mathrm{C}$ (a) $100 \mathrm{bar}$, (b) $150 \mathrm{bar}$, and (c) $200 \mathrm{bar}$.

2D slice in Fig. 5b shows that the macroporous exibit a significant interconnectivity.

Micro-CT allows also a more objective comparison since the porosity and interconnectivity of the samples can be calculated. The interconnectivity of the scaffold is calculated according to the formula: $I=\left[\left(V_{\text {totalpore }}-V_{\text {totalpore }}\right) / V_{\text {totalpore }}\right] \times 100$, where the volume of the disconnected pore stands for the disconnected pore volume which was defined to be higher than $50 \mu \mathrm{m}$.
The increase of the initial polymer concentration does not influence the porosity of the scaffolds produced (Fig. 6). Instead, the thickness can be tunned just by varying the amount of polymer present in the organic solution. As the volume of the polymer solution is the same for all conditions, higher concentration leads to the production of thicker scaffolds, which vary from $1.5 \mathrm{~mm}$ up to $1.9 \mathrm{~mm}$ when a solution with $10 \mathrm{wt} \%$ or $20 \mathrm{wt} \%$ SPLA is processed.

Mechanical properties of the samples prepared were evaluated and compression tests were performed to the samples prepared
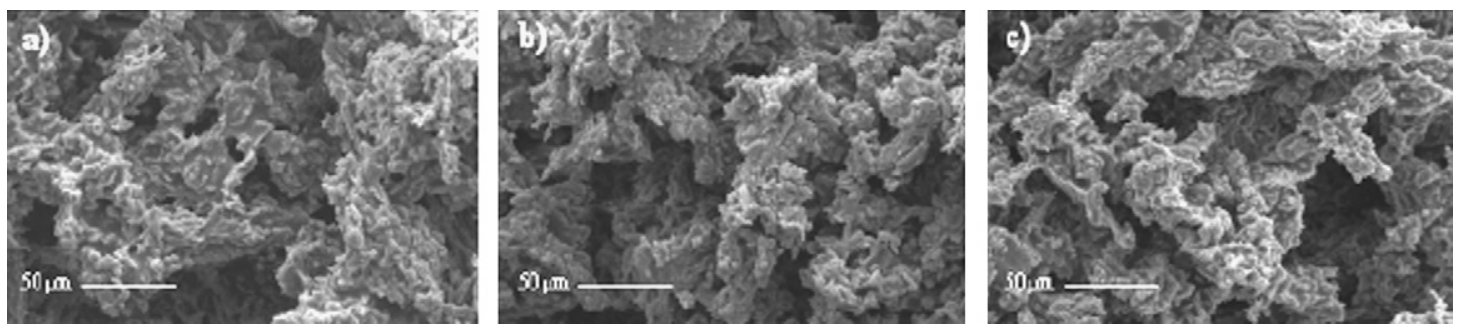

Fig. 10. Effect of temperature in the formation of SPLA porous matrixes, at $100 \mathrm{bar}(\mathrm{a}) 35^{\circ} \mathrm{C}$, (b) $45^{\circ} \mathrm{C}$, and (c) $55^{\circ} \mathrm{C}$.
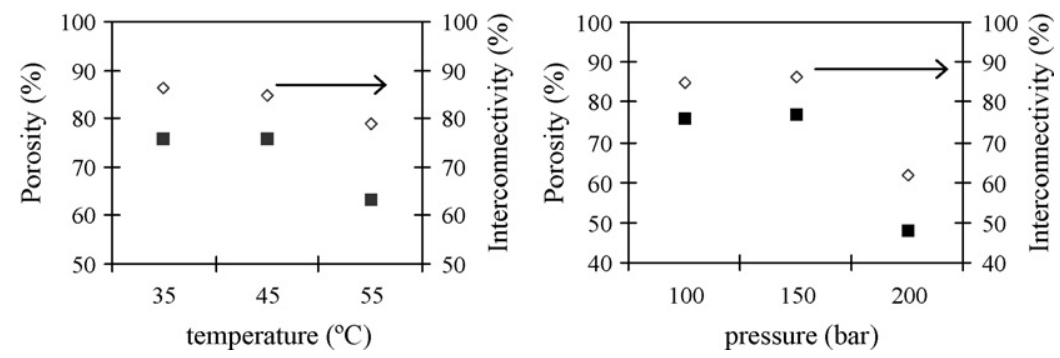

Fig. 11. Effect of pressure and temperature in the porosity $(\boldsymbol{\square})$ and interconnectivity $(\diamond)$ of the structure prepared. 

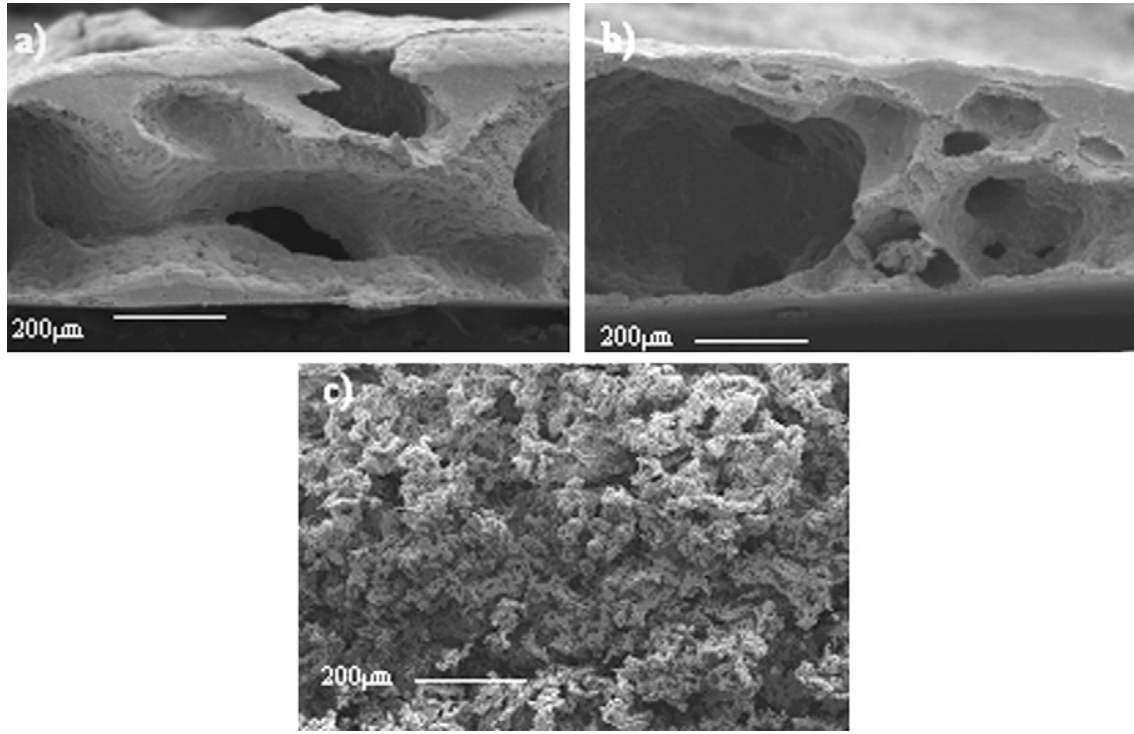

Fig. 12. Porous structures prepared from (a) SPLA 30:70 at 100 bar, $45^{\circ} \mathrm{C}$, (b) SPLA $30: 70$ at 100 bar and $55^{\circ} \mathrm{C}$, and (c) SPLA $50: 50$ at 100 bar and $45^{\circ} \mathrm{C}$.

with different polymer concentrations. Fig. 7 shows, as an example, a representative curve for the deformation behaviour of the porous matrixes, namely for a sample prepared with $20 \%$ SPLA.

A summary of the results, which are a mean value of at least five experiments, is presented in Table 2.

In Fig. 8, the relationship between the compressive modulus and the polymer concentration is highlighted. As expected a higher concentration of the material gives more stiffness to the material and therefore, the modulus tends to be higher. In the same way, the stress of the material also increases with the higher concentration of SPLA. On the contrary, increasing polymer concentration tends to decrease the strain at maximum stress.

\subsubsection{Effect of pressure and temperature}

The effect of pressure the porosity was studied for the system SPLA (10 wt\% polymer solution) for three different temperatures. As an example, a comparison of the different structures prepared at $45^{\circ} \mathrm{C}$ and different pressures is shown in Figs. 9 and 10 elucidates the effect of temperature in the matrixes prepared.

From SEM images we observe that scaffolds prepared at different conditions present a similar morphology, which is very homogeneous in all cases. A major limitation in tissue engineering is the failure to induce rapid vascular ingrowth during tissue development. The viability of cells that migrate into the scaffold from the native tissue is highly dependent on transport of nutrients and waste products between the cells and the host tissue [35]. Therefore, the high interconnectivity of the implant is extremely important for the success of the bone defect repairment. Fig. 11 represents the trend of the matrix porosity and interconnectivity as a function of these two processing parameters.

Although the temperature effect is not as pronounced as the pressure effect we can observe a slight decrease in the porosity of the samples prepared at higher temperatures. A possible explanation for this is the fact that at lower temperatures the demixing process is slower and so is the growth of droplets of the polymer lean phase which is translated in a higher average pore size.

The pressure effect is more related to the solvent power of carbon dioxide. As pressure decreases, there is a reduction in the carbon dioxide density and therefore a reduction in the solvent power of $\mathrm{CO}_{2}$. At lower pressures, the affinity of the $\mathrm{sc}^{\mathrm{CO}}$ to the organic solvent decreases and the cell size increases because of the formation of a larger quantity of the polymer lean phase. Fur- thermore, higher pressures result in a compression of the matrixes. For this reason, the scaffolds prepared at 200 bar present a lower porosity.

\subsection{SPLA (30:70wt\%) scaffolds}

Another commercial blend of SPLA (30:70 wt\%), with a higher content in PLLA was tested. Fig. 12 presents the SEM images of a cross-section of the scaffolds prepared with $10 \mathrm{wt} \%$ at $100 \mathrm{bar}$ and 45 and $55^{\circ} \mathrm{C}$. When analysing these cross-sections no substantial differences are observed from samples prepared at $45^{\circ} \mathrm{C}$ or $55^{\circ} \mathrm{C}$.

Comparing the matrixes from SPLA (30:70wt\%) and SPLA (50:50 wt\%) it becomes clear that a higher content in PLLA leads to the production of a more heterogeneous matrix with bigger porous.

We can conclude from the results that the morphology of the porous structures obtained in blends of starch and PLLA is highly dependent on the composition. Therefore, this parameter can be used to produce scaffolds with different porosities and pore sizes, tailored for a particular application.

\section{Conclusions}

In this work, the feasibility of preparing porous structures of a natural-based polymeric systems using supercritical assisted phase-inversion method was evaluated.

Different parameters that influence the process were tested. Scaffolds prepared with SPLA 50:50 wt\% show that a bicontinuous structure if formed which indicates that the mechanism governing the precipitation of these interconnected pore structures is the spinodal decomposition. However, this is still object of discussion and another hypothesis is that the bicontinuous structures are a result of coalescence of polymer poor droplets generated by bimodal decomposition. The initial concentration of polymer solution does not affect the porosity of the scaffolds produced however, the thickness of the samples can be tunned when this parameter is varied.

From the results obtained it is possible to conclude that pressure is the parameter that most affect the porosity, interconnectivity and pore size of the structure prepared. A comparison between the matrixes prepared at different temperatures demonstrates that this parameter does not play an important role in the morphology or porosity of the scaffolds prepared. 
Blends of SPLA 50:50 wt\% and 30:70 wt\% were processed, however the presence of a much higher concentration of PLLA in the blend produces structures exhibiting bigger and more heterogeneous pores.

The preparation of a highly porous and interconnected structure of a starch-based material using a clean and environmentally friendly technology constitutes a new processing technology for the preparation of scaffolds for tissue engineering using these materials. We believe that such methodology could be adapted to prepare porous structures using other natural-based polymeric systems.

\section{Acknowledgment}

Ana Rita C. Duarte is grateful for financial support from Fundação para a Ciência e Tecnologia through the grant SFRH/BPD/34994/2007.

\section{References}

[1] X. Liu, P.X. Ma, Polymeric scaffolds for bone tissue engineering, Annals of Biomedical Engineering 32 (3) (2004) 477.

[2] J.F. Mano, G.A. Silva, H.S. Azevedo, P.B. Malafaya, R.A. Sousa, S.S. Silva, L.F. Boesel, J.M. Oliveira, T.C. Santos, A.P. Marques, N.M. Neves, R.L. Reis, Natural origin biodegradable systems in tissue engineering and regenerative medicine: present status and some moving trends, Journal of the Royal Society Interface 4 (17) (2007) 999.

[3] J.M. Dang, K.W. Leong, Natural polymers for gene delivery and tissue engineering, Advanced Drug Delivery Reviews 58 (2006) 487.

[4] P.B. Malafaya, G.A. Silva, R.L. Reis, Natural-origin polymers as carriers and scaffolds for biomolecules and cell delivery in tissue engineering applications, Advanced Drug Delivery Reviews 59 (4-5) (2007) 207.

[5] M.E. Gomes, R.L. Reis, Biodegradable polymers and composites in biomedical applications from catgut to tissue engineering Part I.: available systems and their properties, International Materials Reviews 49 (5) (2004) 261.

[6] A.J. Salgado, O.P. Coutinho, R.L. Reis, J.E. Davies, In vivo response to starch based scaffolds for bone tissue engineering applications, Journal of Biomedical Materials Research Part A 80 (4) (2007) 983.

[7] M.E. Gomes, R.L. Reis, Biodegradable polymers and composites in biomedical applications from catgut to tissue engineering. Part II: systems for temporary replacement and advanced tissue regeneration, International Materials Reviews 49 (5) (2004) 274.

[8] S. Ghosh, J.C. Viana, R.L. Reis, J.F. Mano, The double porogen approach as a new technique for the fabrication of interconnected poly(L-lactic acid) and starch based biodegradable scaffolds, Journal of Materials Science: Materials in Medicine 18 (2) (2007) 185

[9] S. Ghosh, J.C. Viana, R.L. Reis, J.F. Mano, Development of porous lamellar poly(L-lactic acid) scaffolds by conventional injection molding process, Acta Biomaterialia 4 (4) (2008) 887.

[10] L.F. Boesel, J.F. Mano, C. Elvira, J. San Roman, R.L. Reis, Hydrogels and hydrophilic partially degradable bone cements based on biodegradable blends incorporating starch, in: E. Chiellini (Ed.), Biodegradable Polymers and Plastics, Kluwer Academic, Dordrecht, 2003.

[11] L.F. Boesel, J.F. Mano, R.L. Reis, Optimization of the formulation and mechanical properties of starch based partially degradable bone cements, Journal of Materials Science: Materials in Medicine 15 (2004) 73.

[12] P.B. Malafaya, C. Elvira, A. Gallardo, J. San Roman, R.L. Reis, Porous starch-based drug delivery systems processed by a microwave treatment, Journal of Biomaterials Science, Polymer 12 (11) (2001) 1227.

[13] P.B. Malafaya, F. Stappers, R.L. Reis, Starch-based microspheres produced by emulsion crosslinking with a potential media dependent responsive behavior to be used as drug delivery carriers, Journal of Materials Science: Materials in Medicine 17 (2006) 371.

[14] G.A. Silva, J. Costa, O.P. Coutinho, S. Radin, P. Ducheyne, R.L. Reis, Synthesis and evaluation of novel bioactive composite starch/bioactive glass microparticles, Journal of Biomedical Materials Research Part A 70A (2004) 442

[15] D.W. Hutmacher, Scaffold design and fabrication technologies for engineering tissues-state of the art and future perspectives, Journal of Biomaterials Science, Polymer 12 (2001) 107.

[16] R.A. Quirk, R.M. France, K.M. Shakesheff, S.M. Howdle, Supercritical fluid technologies and tissue engineering scaffolds, Current Opinion in Solid State and Materials Science 8 (2004) 313.

[17] D.L. Tomasko, H. Li, D. Liu, X. Han, M.J. Wingert, L.J. Lee, K.W. Koelling, A review of $\mathrm{CO}_{2}$ applications in the processing of polymers, Industrial Engineering and Chemical Research 42 (2003) 6431.

[18] I. Kikic, P. Sist, Applications of supercritical fluids to pharmaceuticals: controlled drug release systems, in: E. Kiran, P.G. Debenedetti, C.J. Peters (Eds.), Supercritical Fluids: Fundamentals and Applications, Proceedings of the 2nd NATO ASI on Supercritical Fluids; NATO Science Series, Kluwer, Dordrecht, The Netherlands, 2000, p. 291.

[19] O.R. Davies, A.L. Lewis, M.J. Whitaker, H. Tai, K.M. Shakesheff, S.M. Howdle, Applications of supercritical $\mathrm{CO}_{2}$ in the fabrication of polymer systems for drug delivery and tissue engineering, Advanced Drug Delivery Reviews 60 (3)(2007) 373.

[20] A.I. Cooper, Porous materials and supercritical fluids, Advanced Materials 15 (13) (2003) 1049

[21] I. Tsivintzelis, E. Pavlidou, C. Panayiotou, Porous scaffolds prepared by phase inversion using supercritical $\mathrm{CO}_{2}$ as antisolvent: I. Poly(L-lactic acid), Journal of Supercritical Fluids 40 (2007) 317.

[22] I. Tsivintzelis, S.I. Marras, I. Zuburtikudis, C. Panayiotou, Porous poly(L-lactic acid) nanocomposite scaffolds prepared by pahse inversion using supercritical $\mathrm{CO}_{2}$ as antisolvent, Polymer 48 (2007) 6311

[23] E. Reverchon, S. Cardea, E.S. Rappo, Production of loaded PMMA structures using the supercritical $\mathrm{CO}_{2}$ phase inversion process, Journal of Membrane Science 273 (2006) 97.

[24] Y.W. Kho, D.S. Kalika, B.L. Knutson, Precipitation of nylon 6 membranes using compressed carbon dioxide, Polymer 42 (2001) 6119.

[25] H. Matsuyama, A. Yamamoto, H. Yano, T. Maki, M. Teramoto, K. Mishima, K. Matsuyama, Formation of porous flat membranes by phase separation with supercritical $\mathrm{CO}_{2}$, Journal of Membrane Science 194 (2001) 157.

[26] H. Matsuyama, A. Yamamoto, H. Yano, T. Maki, M. Teramoto, K. Mishima, K. Matsuyama, Effect of organic solvents on membrane formation by phase separation with supercritical $\mathrm{CO}_{2}$, Journal of Membrane Science 204 (2002) 81.

[27] E. Reverchon, S. Cardea, Formation of cellulose acetate membranes using a supercritical fluid assisted process, Journal of Membrane Science 240 (2004) 187.

[28] E. Reverchon, S. Cardea, Formation of polysulfone membranes by supercritical $\mathrm{CO}_{2}$, Journal of Supercritical Fluids 35 (2005) 140.

[29] M. Temtem, T. Casimiro, J.F. Mano, A. Aguiar-Ricardo, Preparation of membranes with polysulfone/polycaprolactone blends using a high pressure cell specially designed for a $\mathrm{CO}_{2}$-assisted phase inversion, Journal of Supercritical Fluids 43 (2008) 542

[30] M. Temtem, T. Casimiro, A. Aguiar-Ricardo, Solvent power and depressurization rate effects in the formation of polysulfone membranes with $\mathrm{CO}_{2}$-assisted phase inversion method, Journal of Membrane Science 283 (2006) 244.

[31] M.-S. Kim, S.-J. Lee, Characteristics of porous polycarbonate membrane with polyethylene glycol in supercritical $\mathrm{CO}_{2}$ and effect of its porosity on tearing stress, Journal of Supercritical Fluids 31 (2004) 217

[32] H. Tompa, Polymer Solutions, Butterworths, London, 1956

[33] P. van de Witte, P.J. Dijkstra, J.W.A. van de Berg, J. Feijen, Phase separation processes in polymer solutions in relation to membrane formation, Journal of Membrane Science 117 (1996) 1.

[34] K. Kimmerle, H. Strathmann, Analysis of the structure-determining processes of phase inversion membranes, Desalination 79 (1990) 283.

[35] W.L. Murphy, M.C. Peters, D.H. Kohna, D.J. Mooney, Sustained release of vascular endothelial growth factor from mineralized poly(lactide-co-glycolide) scaffolds for tissue engineering, Biomaterials 21 (2000) 2521 